P86 AUDIT ON THE MANAGEMENT OF WOMEN WITH SYPHILIS IN THE NORTH EAST OF ENGLAND

doi:10.1136/sextrans-2012-050601c.86

${ }^{1} \mathrm{Y}$ Hew, ${ }^{2} \mathrm{~K}$ Foster, ${ }^{1} \mathrm{~L}$ Mitchell, ${ }^{3} \mathrm{~T}$ Suchak, ${ }^{4} \mathrm{~V}$ Wholey, ${ }^{5} \mathrm{~B}$ Elawad, ${ }^{6} \mathrm{M}$ Basta, ${ }^{7} \mathrm{~J}$ Hussey. ${ }^{1}$ New Croft Centre, Newcastle Upon Tyne, UK; ${ }^{2} H P A ;{ }^{3}$ University Hospital North Durham, Durham, UK; ${ }^{4}$ Darlington Memorial Hospital, Durham, UK; ${ }^{5}$ One to One Centre, Shiremoor, UK; ${ }^{6}$ Gateshead GUM; ${ }^{7}$ Sunderland Royal Hospital, Sunderland, UK

Background The increase in syphilis in women over the last 10 years in the North East and re-emergence of congenital syphilis, as presented at BASHH spring meeting 2011, prompted a review of current management of pregnant women with syphilis.

Objectives To identify any risk factors in women being diagnosed with syphilis in the region and to review the current management of pregnant women with syphilis.

Methods A regional audit involving all Genitourinary Urinary Medicine (GUM) departments in the North East was conducted. Case notes of all women diagnosed with syphilis from 2006 to 2010 were obtained to identify risk factors in the women and to review the management, communication, follow-up and outcome of pregnant women with syphilis. Standards were set against current BASHH guidelines on syphilis management and local standards.

Results A total of 98 women were diagnosed with syphilis over the 5 years. $61 \%$ of all women were White British. 42/98 women were pregnant. $27 \%$ of non-pregnant women had infectious syphilis compared to $42 \%$ of pregnant women. $23 \%$ had another concurrent sexually transmitted disease. Most women were in a regular relationship with only 17 women reporting a casual partner in the last 3 months. Overall $41 \%$, but only $7 \%$ of white British women, had had sex with a man from overseas. There were two cases of confirmed congenital syphilis and five early miscarriages. Documentation of excluded congenital syphilis was poor (only three cases) in GUM records.

Conclusion The high level of infectious syphilis in pregnant women and poorly documented outcomes has informed a multi-disciplinary good practice arrangement to be produced and promoted to improve communication between clinicians, ensure recommended treatment and follow-up. No clear risk factor groups were found to inform repeat testing in later pregnancy. A new enhanced surveillance form is soon to be piloted which includes collecting data on birth outcomes.

\section{P87 DEVELOPMENT OF REGIONAL GOOD PRACTICE ARRANGEMENTS FOR THE MANAGEMENT OF PREGNANT WOMEN WITH SYPHILIS AND THEIR BABIES IN THE NORTH EAST OF ENGLAND}

doi:10.1136/sextrans-2012-050601c.87

${ }^{1} \mathrm{Y}$ Hew, ${ }^{*}{ }^{2} \mathrm{~J}$ Hussey, ${ }^{1} \mathrm{~L}$ Mitchell, ${ }^{3} \mathrm{M}$ Vallappil, ${ }^{4} \mathrm{~J}$ Clarke, ${ }^{5} \mathrm{~J}$ Clarke, ${ }^{3} \mathrm{~K}$ Foster. ${ }^{1} \mathrm{New}$ Croft Centre, Newcastle upon Tyne, UK; ${ }^{2}$ Sunderland Royal Hospital, Sunderland, UK; ${ }^{3} \mathrm{HPA} ;{ }^{4}$ Royal Victoria Infirmary, Newcastle upon Tyne, UK; ${ }^{5}$ Royal Victoria Hospital, Barrie, Ontario, Canada

Background The re-emergence of congenital syphilis in the North East and outcomes of a regional audit prompted the development of regional good practice arrangements in managing pregnant women with syphilis and their babies.

Aims Guidance documents for the various clinical specialties were present for the management of pregnant women with syphilis in our region, but not a clear description of the whole patient (mother and baby) pathway. The overall aim of the good practice arrangement was to clarify precise roles of clinicians looking after these pregnant women, prompt re-testing of syphilis based on subsequent risks and concerns, create referral pathways and encourage multidisciplinary communication in management of pregnant women with syphilis.

Method Current national guidance was reviewed and discussed between Northern BASHH group, Health Protection Agency (HPU and virology), regional Paediatric Infectious Diseases and Antenatal screening coordinators. Audit outcomes highlighted areas needing improvement and these were addressed including use of named rather than numbered GUM serology specimens.

Results The good practice arrangement outlines clearly the patient journey from diagnosis to delivery and follow-up of her baby. It is divided into different stages, with each outlining clearly who is responsible for care, locally recommended practice and referring to national guidance where indicated for the management of that stage. These stages are antenatal screening and referral process to GUM, management of positive results in mother, investigations of baby at birth, follow-up of babies born to mothers with positive syphilis results and treatment of baby with suspected congenital syphilis. Good practice is included on the management of mothers who do not attend GUM follow-up, communication to those involved in care and a named lead paediatrician in every hospital trust in the North East region has been created.

\section{P88 ULIPRISTAL ACETATE (UPA) IS AFFORDABLE AS EMERGENCY CONTRACEPTION (EC) IF USED WHERE LEVONORGESTREL (LNG) IS UNLICENSED}

doi:10.1136/sextrans-2012-050601c.88

A B Jones, ${ }^{*}$ L Dominguez Garcia, C E Cohen, N Nwokolo, S L Day. Chelsea and Westminster Hospital, London, UK

Background/Aim Our three GUM clinics are increasingly offering an integrated family planning (FP) service. We audited against three Faculty of Sexual and Reproductive Health EC standards. UPA is licensed to be given as EC following an extended window period $(<120 \mathrm{~h})$ after unprotected sex (UPSI)) compared to LNG $(<72 \mathrm{~h})$ but, is prohibitively more expensive (LNG £6.65, UPA £20.35). We estimated the anticipated cost to our service by introducing UPA to the GUM formulary.

Methods Electronic notes review of patients prescribed EC between 1st December 2010 and 1st March 2011

Results The case notes of 163 EC prescriptions were reviewed. The median age was 24 years and $58.9 \%$ were Caucasian. The Faculty of Sexual and Reproductive Health standards were not achieved (Aim 100\%): discuss future contraception (95\%); offer STI screening (90\%); offer an intrauterine device (Cu-IUD) (54\%). 33\% $(54 / 163)$ of patients received a method of general contraception on the day of EC prescription. Of those that did not: 19\% (21/109) booked an FP appointment at which $62 \%$ received general contraception and 38\% did not attend; $12 \%$ (13/109) returned for more EC and at one site 4\% (2/49) returned pregnant (not EC failures). $4.3 \%(7 / 163)$ of EC prescriptions were outside the product license for LNG but within license for UPA (UPSI $72-120 \mathrm{~h}$ ago or multiple episodes of UPSI within $120 \mathrm{~h}$ ). Using this as an estimate of UPA service need, this equates to an additional expenditure of $£ 383.60$ /year though, this is likely an underestimate given LNG may not be routinely offered outside its license and is of uncertain efficacy beyond $72 \mathrm{~h}$.

Recommendations Extended provision of $\mathrm{Cu}$-IUD fittings is required to improve offer/uptake rates of this first line EC methodcurrent availability is limited to $1-3$ sessions/wk. In light of high default rates clinicians should consider quick starting/ dispensing general contraception when prescribing EC. Further FP integration is planned to facilitate this. UPA seems affordable in GUM. 